\title{
Identification of thorium dioxide in human liver cells by electron microscopic $x$-ray microanalysis
}

\author{
ARNE ØDEGAARD, EGIL M. OPHUS, AND AILEEN M. LARSEN \\ From the Department of Pathology, Trondheim Regional Hospital, 7000 Trondheim, Norway
}

SUMmaRY Thirty-two years after injection of thorium dioxide (Thorotrast) for diagnostic $x$-ray studies in a female patient deposits were found by light microscopy in the liver macrophages (Kupffer cells). They were shown by electron microscopy to be located inside secondary lysosomes, and by autoradiography and $x$-ray microanalysis they were identified as thorium.

The aim of the present study was to undertake an ultrastructural examination of liver cells obtained by biopsy from a 47-year-old woman who in 1945 had received an unknown amount of thorium dioxide (Thorotrast) intravenously for diagnostic $x$-ray purposes before the removal of a brain tumour. The deposits of Thorotrast in the liver and spleen were discovered incidentally during $x$-ray examination of the kidney for an intercurrent disease. The biopsy was taken specifically for morphological study of the liver. The intracellular presence and localisation of aggregates of thorium dioxide particles was studied using light microscopic autoradiography and electron microscopic $x$-ray microanalysis. The latter technique has proved a valuable tool for the identification of elements naturally occurring in biological samples as well as in exogenously introduced elements. To our knowledge, this is the first study demonstrating thorium dioxide (Thorotrast) in liver cells by $x$-ray microanalysis.

\section{Material and methods}

Tissue from needle biopsy of the liver was fixed immediately in $4 \%$ glutaraldehyde in $0.1 \mathrm{M}$ cacodylate buffer at pH $7 \cdot 2$. One-half of the tissue was prepared for electron microscopy while the other was transferred to buffered formalin and processed by routine histological methods.

Paraffin-embedded sections, $5 \mu \mathrm{m}$ thick, were deparaffinised, dehydrated, and coated with Kodak nuclear track emulsion NTB 2 for autoradiography. The emulsion-coated slides were stored in darkness at $4^{\circ} \mathrm{C}$. After four weeks they were developed and stained with haematoxylin and eosin.

Received for publication 13 February 1978
The material for electron microscopic studies was transferred to a mixture with a final concentration of $2 \%$ glutaraldehyde and $2 \%$ osmium tetroxide buffered to $\mathrm{pH} 7 \cdot 2$ by $0 \cdot 1 \mathrm{M}$ cacodylate. After one hour the tissue was washed in buffer and postosmification was carried out in $2 \% \mathrm{OsO}_{4}$ for one hour (Franke et al., 1969). Subsequently the tissue was dehydrated and embedded in Epon 812. All substances used for preparation were of high chemical purity with an insignificant amount of thorium. Sections approximately $60 \mathrm{~nm}$ thick, judged from interference colours, were cut with glass knives, mounted on copper grids, and examined in a Zeiss EM-9S-2 electron microscope at $60 \mathrm{keV}$. Some sections were examined without prior staining, others after staining with uranyl acetate and lead citrate (Reynolds, 1963). For electron microscopic $x$-ray microanalysis unstained sections, about $150 \mathrm{~nm}$ thick, were mounted on copper grids and analysed in a Transmission Electron Microscope (Phillips 300) equipped with an energy dispersive $x$-ray analysis system (EDAX). The electron microscope was operated at $100 \mathrm{kV}$ with a specimen tilt of 42 degrees. Analysing time was 55 seconds.

\section{Results}

MORPHOLOGICAL FINDINGS

\section{Light microscopy (Fig. I)}

The hepatic architecture was preserved. A variable amount of granular material was observed in the sinusoidal macrophages (Kupffer cells).

\section{Electron microscopy (Figs 2 and 3)}

In the ultrastuctural study one or more electrondense cytoplasmic inclusions were found within each liver macrophage. The study of $60 \mathrm{~nm}$ thick stained sections revealed that the inclusions lay 


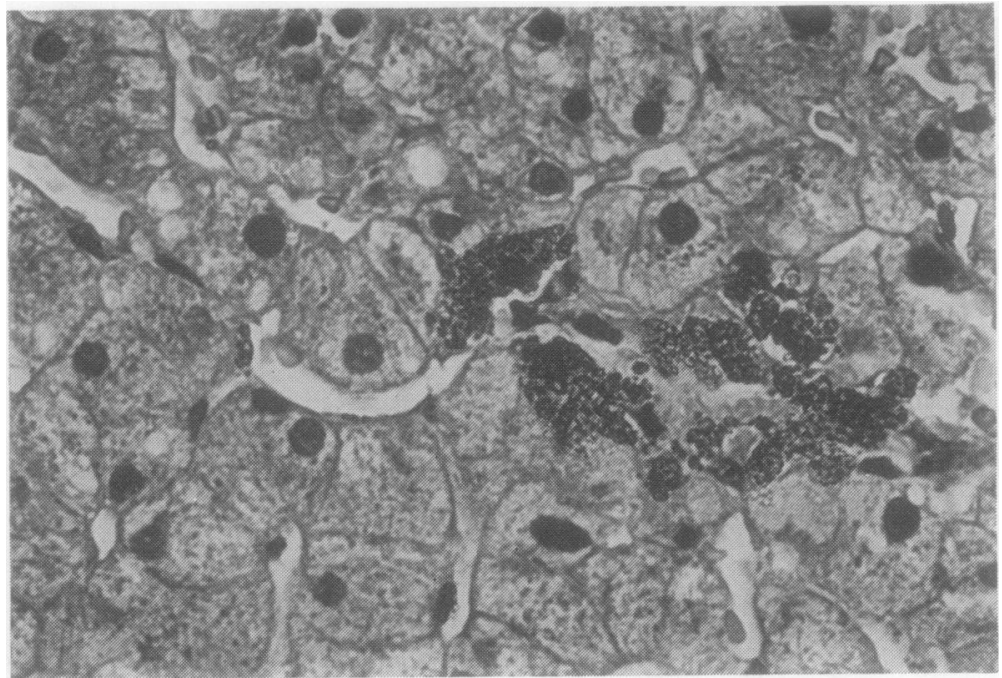

Fig. 1 Liver biopsy specimen with preserved architecture and collection of Thorotrast-containing macrophages (Haematoxylin and eosin $\times 450$ )

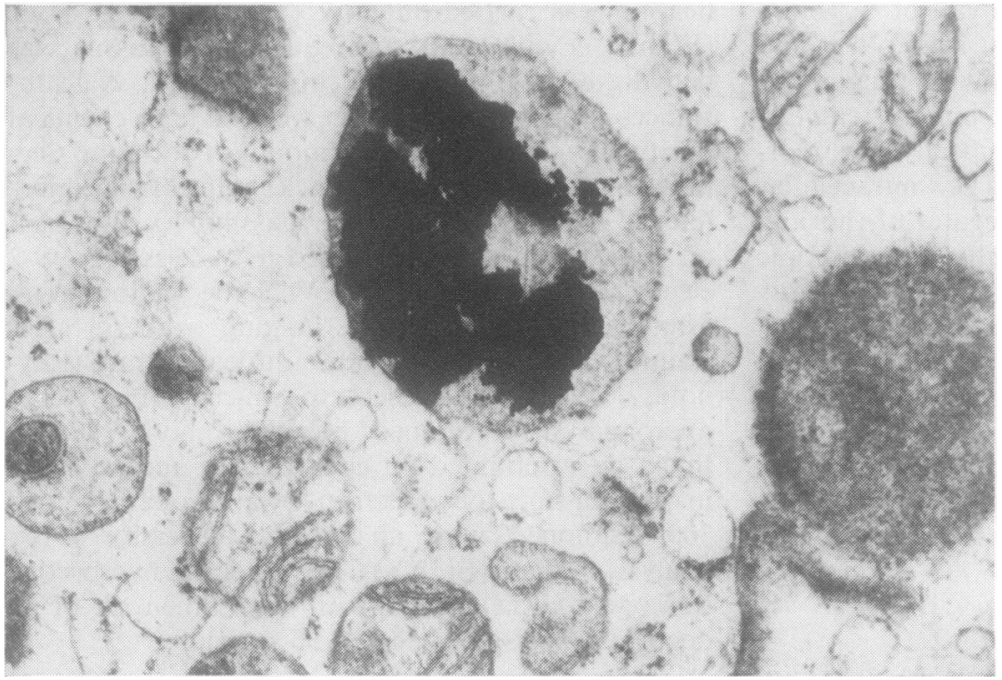

Fig. 2 Electron micrograph showing a residual body containing electron-dense Thorotrast particles in liver macrophage. Uranyl acetate and lead citrate $\times 24000$

inside single-membrane bound cell organelles, identified as residual bodies (Fig. 2). Some of these bodies were completely filled with the dense material. In some instances electron-dense inclusions could be demonstrated inside autophagic vacuoles (Fig. 3).

\section{Electron microscopic $\mathrm{x}$-ray microanalysis (Figs 4} and 5)

In the semithick unstained sections prepared for $x$-ray microanalysis little cellular detail and no membranes could be identified. However, the electron dense inclusions were easily located (Fig. 4). Figure 5 shows the $x$-ray spectrum from microanalysis of the heavily loaded cells shown in Figure 4. The spectrum shows prominent thorium peaks (M-line at $3.06, \mathrm{~L}_{\alpha}$ at $12.96, \mathrm{~L}_{\beta 1}$ at $16 \cdot 19, \mathrm{~L}_{\beta 2}$ at 15.62 , and $L_{\gamma}$ at $18.92 \mathrm{keV}$, respectively). None of these peaks was present in the spectrum from an adjacent cell without electron-dense inclusions. The other peaks present in Fig. 5 represent elements $(\mathrm{P}, \mathrm{Cl}, \mathrm{Cr}, \mathrm{Ni}, \mathrm{Cu}, \mathrm{Zn}, \mathrm{Os}$ ) in the fixative, embedding material, and metal-containing parts of the ana- 


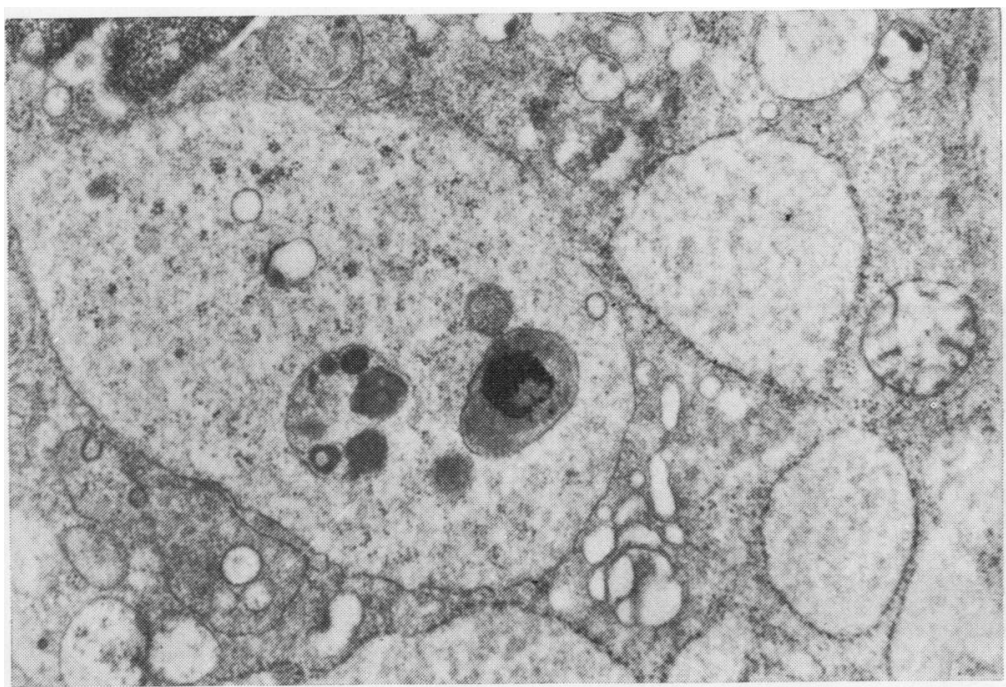

Fig. 3 Electron micrograph showing autophagic vacuole with heterogenous granules. Liver macrophage. Uranyl acetate and lead citrate $\times 14000$

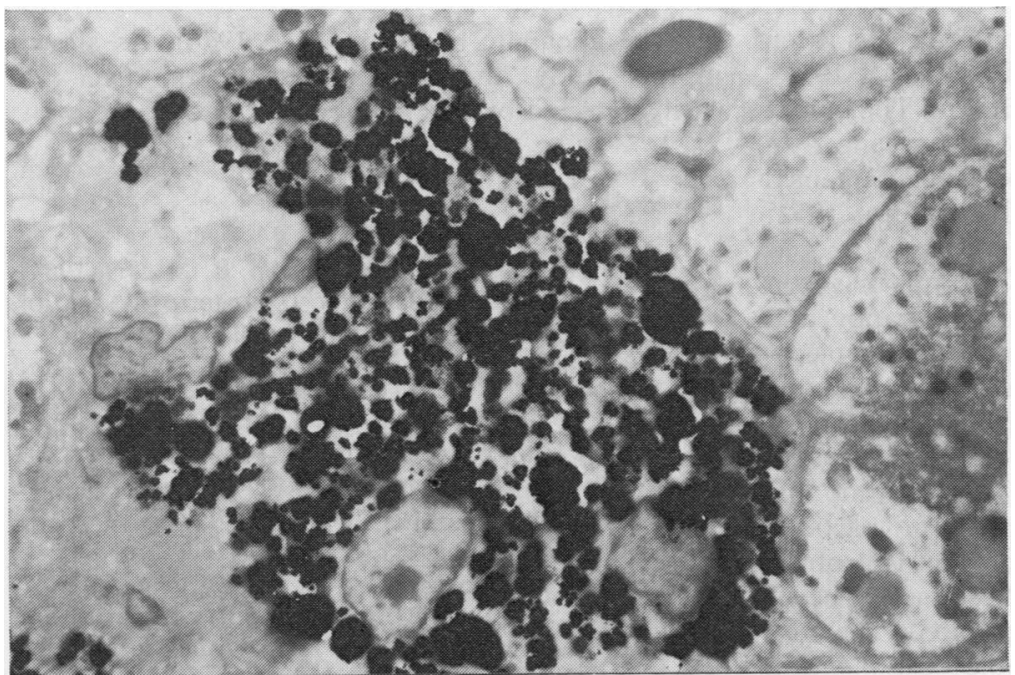

Fig. 4 Semithick section $(150 \mathrm{~nm})$ of liver macrophage heavily loaded with inclusions of Thorotrast. Unstained $\times 14000$

lysing instrument. These peaks were present in all the $x$-ray spectra.

Autoradiography disclosed some short, straight tracks emanating in a spokelike fashion from the thorium inclusions, typical of those produced by alpha particles.

The patient's present condition is excellent, without signs of liver disease.

\section{Discussion}

The ultimate fate of phagocytosed material depends not only on the function of the lysosomal apparatus but also on the nature of the ingested material. Digestible organic substances are broken down and may enter the metabolism as simpler compounds. On the other hand, phagocytosed material resistant to the lysosomal enzymes is stored indefinitely in residual bodies. Depending on the quantity and type, such material may be injurious. An example of a potentially hazardous material is radioactive Thorotrast particles. Thorotrast, a colloidal solution of thorium dioxide, was used widely some 30 years ago as a contrast medium for diagnostic $X$-ray purposes. Thorotrast contains the radioactive isotope, thorium-232, which is a nearly pure alpha 


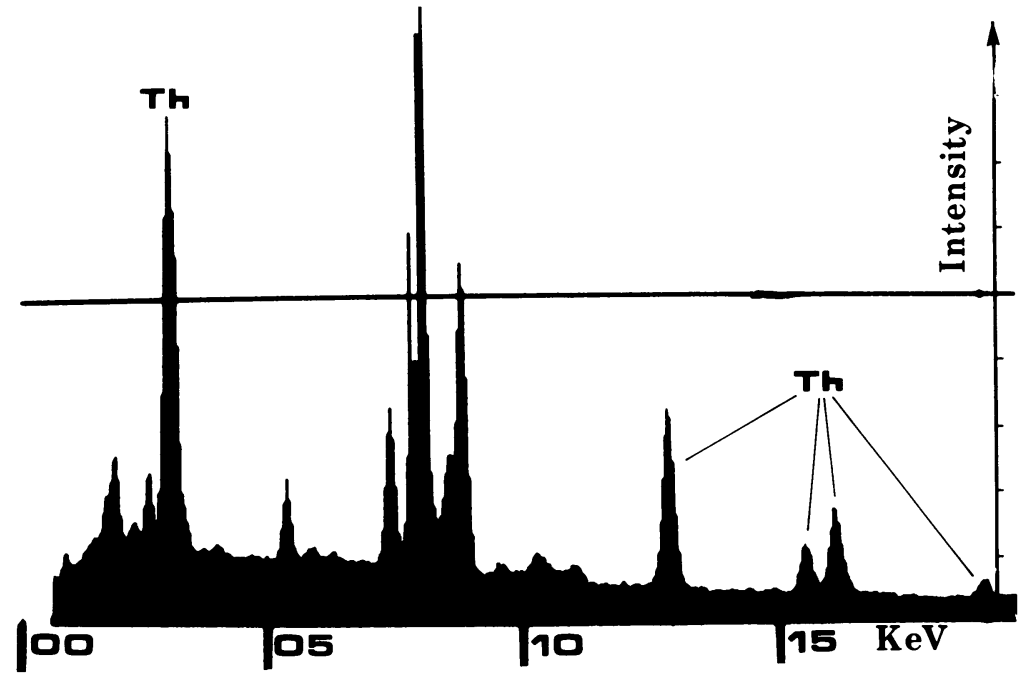

Fig. 5 X-ray spectrum from microanalysis of liver macrophage (Fig. 4) showing characteristic thorium peaks (Th). Non-labelled peaks represent various other elements from the preparation procedure and the instrument (see text). particle emitter. Its biological half-life has been calculated to be over 400 years (Hursh et al., 1957).

There is a voluminous literature on Thorotrast and the liver. The induction of liver cancer in individuals with Thorotrast deposits has gained particular attention (Smoron and Battifora, 1972; Kiely et al., 1973).

In these studies the presence of Thorotrast has been proved by light microscopic autoradiography and by morphological studies with the electron microscope. However, only analytical electron microscopy can determine in situ the exact elementary composition of the deposits.

In this study we identify and demonstrate the sub-cellular localisation of Thorotrast particles injected more than 30 years ago. The Thorotrast particles were mainly located in liver macrophages (Kupffer cells). The liver tissue appeared otherwise undamaged. Electron microscopic examination showed that the particles were retained inside residual bodies. With the analytical electron microscope it was possible to identify thorium-containing deposits.

A major limiting factor in $x$-ray microanalysis is the possible loss and redistribution of elements during conventional preparation techniques (Morgan et al., 1975). Fixation and embedding of the tissue may further introduce new elements into the substrate to be analysed. Nevertheless, when firmly bound elements are investigated, the routine preparation for transmission electron microscopy may be adequate (Yarom et al., 1976). As shown in this study, thorium deposits in the liver are easily detected by this method.

\section{References}

Franke, W. W., Krien, S., and Brown, R. M., Jr. (1969). Simultaneous glutaraldehyde-osmium tetroxide fixation with postosmication. Histochemie, 19, 162-164.

Hursh, J. B., Stedman, L. T., Looney, W. B., and Colodzin, M. (1957). Excretion of thorium and thorium daughters after Thorotrast administration. Acta Radiologica, 47, 481-498.

Kiely, J. M., Titus, J. L., and Orvis, A. L. (1973). Thorotrast-induced hepatoma presenting as hyperparathyroidism. Cancer, 31, 1312-1214.

Morgan, A. J., Davies, T. W., and Erasmus, D. A. (1975). Changes in the concentration and distribution of elements during electron microscopic preparative procedure. Micron, 6, 11-23.

Reynolds, E. S. (1963). The use of lead citrate at high $\mathrm{pH}$ as an electron opaque stain for electron microscopy. Journal of Cell Biology, 17, 208-213.

Smoron, G. L., and Battifora, H. A. (1972). Thorotrastinduced hepatoma. Cancer, 30, 1252-1259.

Yarom, R., Peters, P. D., and Hall, T. A. (1976). Preparation of tissues and cells for $x$-ray microanalysis. Sixth European Congress on Electron Microscopy, 2, 232-234.

Requests for reprints to: Dr Arne Ødegaard, Department of Pathology, The Norwegian Radium Hospital, Montebello, Oslo 3, Norway. 